\title{
Multinational perspective on health care delivery: private versus government
}

\begin{abstract}
Background: Health care issues in any part of the world can suddenly become a global issue. This was exemplified by the outbreak of Ebola virus disease in parts of West Africa, that later spread to other parts of West Africa, Europe and United States of America. The major lesson from this is that nations all over the world should also be keenly interested in health issues and health perspectives of not only their country and neighbouring countries but also of the world at large. The question is on a global scale, what is/are the perspective of people about the private health sector? What is/ are the perspective of people on government health care delivery? Are perspectives the same globally? This article aim to study multinational perspective on health care delivery of respondent's country of domicile.
\end{abstract}

Methods: This study was carried out in two places, Amsterdam in Netherland, and Chicago, illinois, United State of America. The information was obtained by administration of a questionnaire after obtaining consent from each individual.

Results: In all, 121 multinational respondent from 32 countries participated in the survey.

Conclusion: There are salient points to note in this survey which include the fact that global perspective on health care delivery differs from one country to the other. Waiting time is a major issue that a good number of respondents are concerned with. Doctors are not really indicted in almost all countries involved in this survey as the culprit for their countries health care delivery system failure or deficiency in either sector.

Keywords: health care delivery, perspective, multinational, private, government, subsidy

\section{Introduction}

Health care issues in any part of the world can suddenly become a global issue. This was exemplified by the outbreak few years ago of Ebola virus disease in parts of West Africa, Guinea, Sierra Leone and Liberia ${ }^{1,2}$ especially that later spread to other parts of West Africa including Senegal and Nigeria (these two countries were later declared Ebola free by the World Health Organization (WHO) while the outbreak was still on in Liberia especially). Also the spread of infected subjects extended to Europe through air travel (Spain, Germany) (3) and to the United States of America (USA), ${ }^{4-6}$ the USA case being caused by an infected Liberian traveller from West Africa developing and also infecting USA medical personnel.

The major lesson from this is that nations all over the world should also be keenly interested in health issues and health perspectives of not only their country and neighbouring countries but also of the world at large. The first case of Ebola reported in Nigeria was diagnosed in the private health sector before the government was notified and promptly swung into action, this private government partnership was a key factor in the control of Ebola in Nigeria before the feat of being declared Ebola free by WHO was achieved.

The question is on a global scale, what is/are the perspective of people about the private health sector? What is/are the perspective of people on government health care delivery? Are perspectives the same globally? This article aim to study multinational perspective on health care delivery (HCD) outside Nigeria and Nigerians. This scientific
Volume 5 Issue I - 2018

\author{
Ademolu Adegbenga Bolanle \\ Department of Medicine, Lagos State University, Nigeria
}

Correspondence: Ademolu Adegbenga Bolanle, Medicine Department, Lagos State University Teaching Hospital, Ikeja, Lagos, Nigeria, Tel +2348033575940, Email ademoluab@yahoo.com

Received: July 24, 2017 | Published: January 23, 2018 study aim to study peoples perspectives on the HCD of private health services compared to that offered by the government of respondent's country of domicile.

\section{Methodology and study design}

This study was carried out outside Nigeria in two places. The first was in Amsterdam, Netherland, Europe, the second was in Chicago, illinois, United State of America. The information was obtained by administration of a questionnaire after obtaining consent from each individual. The questionnaire stated the aim of the study and composed of two sections A and B. Section A obtained information on the demographic data of the respondent excluding name, only initials were required, information on nationality, gender, age and religion were obtained. Section B contained a 25 stemmed survey question obtaining information on various health perspective issues on private and government HCD.

In all, 121 multinational respondent from 32 countries participated in the survey. The study was designed for those 18 years and above. However, seven under 18 years old were included in the study, one 11years, two 13 years, one 15 years, two 16 years and one 17 years old. There were respondent from Northern and Southern America, Europe, Africa, Asia and Australia. The distribution of respondents according to their nationalities is as follows: United States of America $32.23 \%$, Korean $9.09 \%$, Briton $7.44 \%$, Chinese $5.79 \%$, German 4.96\%, Australian 4.13\%, Brazilian 4.13\%, Mexican 3.31\%, French $2.48 \%$, South African $2.48 \%$, Canadian $2.48 \%$, Indian $1.65 \%$, Iranian 
$1.65 \%$, Dutch 1.65\%, Turkish 1.65\%, Taiwanese 1.65\%, Russian $1.65 \%$, while $0.83 \%$ respondents each are Serbian, Iraq, Jamaican, Saudi Arabian, Japanese, ltalian, Singaporean, Egyptian, Malaysian, Argentine, Bolivian, Austrian, Colombian, Trinidad and Tobago and commonwealth of the Bahamas (Table 1).

Table I Distribution of multinational respondents in percentages (\%)

\begin{tabular}{ll}
\hline Country & Percentage of respondent \\
\hline United states of America (USA) & 32.3 \\
Koreans & 9.09 \\
Briton & 7.44 \\
Chinese & 5.79 \\
German & 4.96 \\
Australian & 4.13 \\
Brazilian & 4.13 \\
Mexican & 3.31 \\
French & 2.48 \\
South African & 2.48 \\
Canadian & 2.48 \\
Indian & 1.65 \\
Dutch & 1.65 \\
Turkish & 1.65 \\
Taiwanese & 1.65 \\
Russian & 1.65 \\
Others & 12.45 \\
\hline
\end{tabular}

\section{Results}

\section{Preference for private health care delivery}

Analysis of this survey showed that $34.71 \%$ (42 multinational respondents) preferred private health care delivery (PHCD) in their country of domicile compared to government health care delivery (GHCD) (Figure 1)

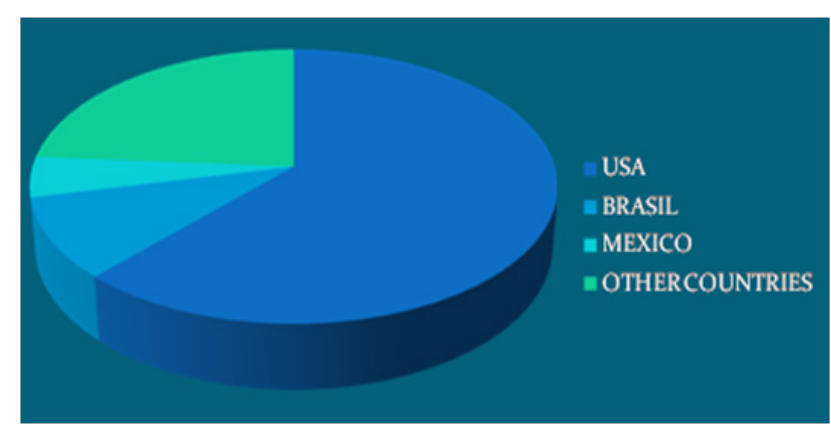

Figure I Percentage distribution of multinational respondents with preference for private health care delivery.

United states of America: US citizens formed 61.90\% (26 respondents) of these; this same Americans formed $70.27 \%$ of all US citizens involved in the survey. According to a USA health care researcher who participated in the survey, she stated that "within the USA, there are no government health care facilities unless you are part of a specific population e.g. a military network or in jail.
Consequently, 1 has no choice but to use private health facility as 1 am not part of any special group". She stated that her reason for the preference is accessibility because there is no government facility, she will advice a friend or acquaintance in USA to attend PHCD. She further stated that she and her employer pays for her health care bill (HCB), she admitted she had a bad personal experience (BPE) in PHCD before but did not disclose the nature, when asked whether private health practitioners are perfect she remained neutral. She admitted she liked doctors, nurses and paramedics level of care in the PHCD in the USA. The reason given by other USA citizen with preference for PHCD include it is better equipped confidentiality is better, there is personal and consistent health care, it gives more options to medical facilities and doctors; another respondent said "l only know about private insurance and it has reasonable costs, not informed on government insurance".

Other US citizen respondent said PHCD is more beneficial, private charges are less; GHCD is not widely available in the USA. A respondent said " 1 want to be treated like an individual real person not a generic patient with a file and private care is better able to do so". I think this perspective speaks the mind of many patients. One respondent stated that government charges are less and that private is better equipped another stated that government outfit are better equipped and private charges are less. Possibly these last two respondents are part of the specific population of US citizen that have access to GHCD within the USA but with divergent perspective. Two under 18 US citizen both indicated that the reason for their preference for PHCD is because it is better equipped.

When asked about which of the outfit will you advice a friend or acquaintance to attend most of the American said PHCD though some said they can advice on any or both. The reasons they cited include: you can get adequate care at either sector, it depends on what you want; some say their advice in support of private is because of better care, some said government is cheaper but private is better quality, one said " 1 haven't had much experience with government facilities but 1 would recommend anywhere that provides adequate health care", some said there are more options in private facilities, one said her advice in favor of private is based on the fact that she is not informed about government insurance, another said he will advice private due to better care if the friend/acquaintance can afford it, one cited comfort as her reason for her advice on choosing private, some say their advice is because private have better doctors and equipments, private are more personable, cheaper and closer to home. One respondent said no GHCD in USA but they have medicare. There are children and women clinic for low income earners or special circumstances. The two under 18 US citizen respondent said they will recommend private depending on which the friend/acquaintance is comfortable with one added affordability as an influencing factor.

Concerning awareness on whether government subsidies HCD or not, $54 \%$ of US citizen respondent said the government does, one cited medicare and Medicaid, 20.8\% said they don't know while the remaining either said no or were silent. The two under 18 respondents said they don't know, this is not unexpected. Furthermore, 30\% of US citizen respondent said the subsidy on HCD by the US government does not influence their preference for PHCD another 30\% said they are not sure if it does, while $16 \%$ affirm that subsidy does, while the remaining respondent were undecided on this issue. As expected the two under 18 respondent were also undecided on the issue. Among the respondents that either said no or not sure whether there is a subsidy or 
not, some insisted that they don't want a subsidy policy while others said they want; one said US government should subsidies those who cannot afford HCD. Their perspective on subsidy varies. Analysis of the survey further showed that $42 \%$ of the respondent cited self as being responsible for their $\mathrm{HCB}, 12.5 \%$ cited self and employer while the other cited employer only, government, medicare, insurance and family.

With respect to bad personal experiences (BPE) in PHCD, 69\% of the US respondents said no ,they have not had such, while 19\% said yes, the other two did not give reasons one complained of terrible services, long waits, another complain of outrageous prices on basic medicines in an emergency visit. One said she have not access PHCD before, though she has preference for them. Of the two under 18 one said no to previous BPE while one has not access PHCD before. When asked whether PHCD are perfect. $8 \%$ strongly agree, 19\% agree, $23 \%$ were neutral, $23 \%$ disagree, $11.5 \%$ strongly disagree, the others were silent despite their preference for PHCD (Figure 2), the two under 18 fell into the silent category here, it is not unexpected of them. This US citizen further stated their likes in PHCD to include: doctors, nurses and paramedics level of care, managerial style, resources available, incentives, opportunity to choose any doctor and personal care as their reasons. They overwhelmingly cited doctors level of care as one of their likes in PHCD in the USA.

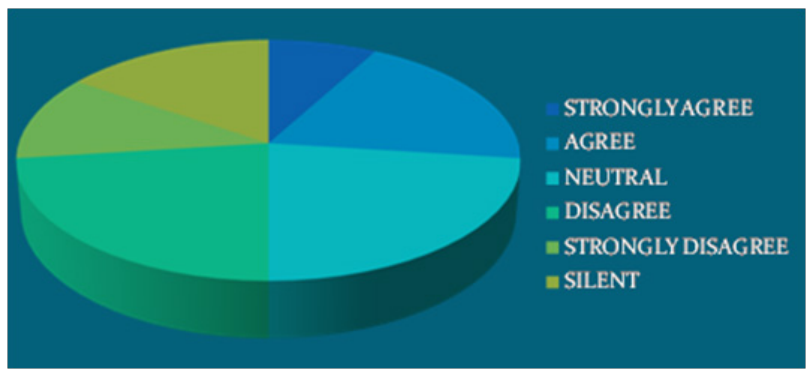

Figure 2 Percentage distribution for Americans (USA) perspective on a perfect private health care delivery.

These group of US respondent offered suggestion that can improve PHCD in USA to include, lowering of charges to make it affordable to poor population ,more patient time, to be non profiting and needs to be less expensive to all and not cost government to get in debt. Other suggest they should be more efficient, one said less government regulation, another said remove subsidies and insurance mandates which drive up costs. One said PHCD should have government stay out of practice and stop dictating, another said there should be less government involvement. Others believe for PHCD to improve in the USA, they must have more appointments while some don't know the advice to give PHCD. While all these US citizen shared a common perspective of preference for $\mathrm{PHCD} / \mathrm{it}$ is obvious from this analysis that there is a marked diversity in their reasons.

Brazil: Brazilians formed $9.52 \%$ of respondents in this survey with preference for PHCD. They formed $80 \%$ (4 out of 5) of Brazilians involved in the survey. Of the 4 Brazilians, $75 \%$ have accessed HCD in both sector while the fourth have accessed only PHCD. The reasons those who have access both health care cited for their preference is that private is better equipped ,the fourth respondent who is a Brazilian lawyer said hers is that services are better there, she stated that she will advice a friend to attend PHCD because of better services, and time spent is less. She stated that her choice of HCD is influenced by accessibility and emergency situation. She is responsible for her health care bill (HCB) and don't know if Brazilian government subsidies HCD, she has not had a BPE in PHCD and agree that private practitioner are perfect. She later admitted she had had a BPE in GHCD before in Brazil in that to see a doctor takes 3-4months, while for surgical operation; it could take 6 months, a long waiting time she said.

She further complained that 200,000 Brazilians lives in the area she lives but there are only two government ambulances to serve that number, she said the Brazilian government need to get more doctors, pharmacists, emergency staffs and hospital ambulances. She admitted that she likes doctors level of care in Brazilian PHCD and affirm that she doesn't like GHCD. She lamented that instead of the Brazilian government to direct financial resources for health sector development they are busy spending huge resources on football (please kindly note that the period of this survey coincided with the time the 2014 Federation international Football Association FIFA world cup was on going in Brazil) and stadia development. She said the good organization of Brazilian PHCD is a reason why she prefers it.

It is very obvious from her comments that while her perspective towards PHCD in Brazil is positive and strong, the same cannot be said of her perspective towards the GHCD. Two of the other three Brazilian involved in the study are Brazilian physicians. They both agreed on their response that PHCD are better equipped, they both said they will advice a friend/acquaintance to attend PHCD. They both admitted that the government subsidies HCD, though these does not influence the decision of neither of them in accessing HCD. One is responsible for her HCB while the other jointly pays with his employer. They have not had a BPE in PHCD, the female physician agrees that PHCD is perfect while the male physician chooses to be neutral. She has not had a BPE in GHCD but strongly disagree that GHCD is perfect. He had had a BPE in GHCD and the experience include long lines (long queues), lack of equipment and no medication, he also strongly disagree that GHCD is perfect .However, they both like doctors level of care in GHCD. They both liked managerial style in PHCD while he further like the nurses and paramedics level of care in Brazilian PHCD.

They both advice the PHCD to charge less while one advice the government to invest more in health and improve managerial style, the other said the Brazilian government needs more money in all areas of health. These are real professional perspectives which if imbibed by the Brazilian government can take HCD in Brazil to the next level. The fourth Brazilian respondent is a biologist. Her perspective is similar to that of the physicians except that she disagree that PHCD is perfect. She said she had had a BPE in GHCD before, she said once they did not want to attend to her because she entered another city. She liked doctor's level of care in both sectors. She advice her government on more number of HCD to be made available.

Mexico: Mexicans formed 4.76\% (2 respondents) with preference for PHCD. They formed $50 \%$ of Mexicans involved in the survey. The two Mexican respondent have accessed both PHCD and GHCD .They said that private are faster and better equipped hence their choice though both admitted that government charges are less .One said he will advice a friend to attend PHCD though it is expensive because there is a better chance to be treated on time. The other said he will advice based on the financial situation of every person, the same respondent admitted if he have all resources at his disposal financially, he will choose private because of earlier appointments and personalized 
health care. He said affordability influences his choice of HCD. The second respondent also said he will choose PHCD if he have all resources because GHCD attention is deficient and they usually don't treat patients on time. He also said affordability influences his choice. The two admitted that on the average PHCD offers satisfactory HCD compared to government. Both also stated that treatment outcomes is better with PHCD.

One stated that the government subsidies HCD while the other don't know. They are both responsible for their HCB, had not had BPE before in PHCD. While one had not had a BPE in GHCD, one had, she said not enough doctors when you need them and death of loved ones out of negligence. Despite her traumatic experience and the resultant perspective, this Mexican lady stated that she likes nursing care in Mexican GHCD system while she admitted she likes doctors level of care in PHCD. She advice Mexican government to get more equipment and to have better schedule in order to improve. She said the private should reduce cost. The second Mexican respondent said he likes the fact that GHCD is more affordable .He also liked the doctors level of care in PHCD. He advised that Mexican government hospitals needs more doctors to meet the number of patients while equally asking for lower rates in PHCD.

Other Countries: The other countries had one respondent each.

Colombia: The only Colombian in the study preferred PHCD because it is better equipped and confidentiality is better. She had accessed both PHCD and GHCD and will advice a friend to attend private as it will give a secure service. She states that private offers satisfactory HCD and treatment outcome is better in it. She cited availability as a factor that influences her choice. She said Colombian government does not subsidies HCD and that she prefers the government does. She is responsible for her HCB and has not had a BPE in PHCD .She agrees that PHCD are perfect. She said she had a BPE in GHCD when she was given long term appointment. She likes doctors level of care in PHCD.

Trinidad and Tobago: According to the only respondent from Trinidad and Tobago, though she had accessed both sectors, her preference is for private because they are better equipped and confidentiality is better. She will advice a friend to attend private because of better quality of HCD which is timely. Accessibility, affordability, availability and emergency situation all influences her choice. She said her country government subsidies HCD, she had not had a BPE in PHCD. She agrees that PHCD is perfect and that the BPE she had in GHCD is that it takes too long. She however strongly disagree that GHCD is perfect. She likes the managerial style, doctors, nurses and paramedics level of care in PHCD. She advised GHCD to be more timely and focus more on quality and patients needs. She advised PHCD to be more affordable.

Britain: One out of 9 Briton (11\%) involved in this survey had preference for PHCD because private is better equipped. She however stated that she can advice a friend to attend both sector, she said both sector gives satisfactory outcome and that if she has all resources financially, she will go for PHCD. Affordability is the main factor that influences her choice of HCD. She said treatment outcome is the same in both sectors. She stated that the government subsidies HCD and that this influences her choice. Her employer pays her HCB, she has not had a BPE in PHCD or GHCD though she disagree that GHCD or PHCD are perfect with a proviso that if PHCD are affordable then they are perfect. She likes doctors, nurses and paramedics level of care in both sector and likes managerial style in PHCD in addition. She was silent on advice to the PHCD or GHCD.

Turkey: One of the two Turkish respondent involved in the survey indicated her preference for PHCD. Though she stated that GHCD are better equipped and that she can advice a friend to attend any sectors, she did not give her reason. She said she cannot say which of the two offers satisfactory HCD and don't know which she will choose if she has all financial resources. Availability influences her choice of HCD. In her perspective, GHCD gives a better treatment outcome though she does not know if Turkish government subsidies HCD or not. She had not had a BPE in PHCD and strongly agrees that PHCD are perfect. She had had a BPE in GHCD. No details were given, however she also strongly agree that GHCD is perfect. She likes doctors level of care in GHCD while she likes nursing care in PHCD. She however offered no advice to either sector.

France: One of the three French citizens (33\%) involved in the survey had preference for PHCD and also will advice an acquaintance on using it. Though, he admitted that GHCD charges are less and gives satisfactory HCD. Accessibility is the factor that influences his choice of HCD.

Iran: One of two Iranian involved in the study indicated preference for PHCD because confidentiality is better and will advice an acquaintance on attending private though she herself had accessed the two sectors before. She said Iranian PHCD offers satisfactory services than government though according to her treatment outcome is better in GHCD. She insisted that if she has all financial resources, she will choose PHCD. Affordability is the factor that influences her choice of HCD. She disclosed that the Iranian government subsidies HCD which influences her choice. Her HCB is payed for by her employer. She had not had BPE in PHCD and agrees that PHCD is perfect. She however had had a BPE in GHCD though no details were given. She was neutral on whether GHCD is perfect or not. She likes doctors level of care in GHCD but was silent on what she likes about PHCD.

Iraq: The only Iraq physician who participated in the survey have preference for PHCD because private is better equipped and confidentiality is better, he has accessed both GHCD and PHCD before. He will advice an acquaintance to attend PHCD though he admitted that he cannot say which sector offers satisfactory HCD. If he has all resources financially he will choose PHCD because it is well equipped, better services is available and less waiting list. The factors that influence his choice of HCD include accessibility, affordability, availability and emergency situation. He said treatment outcome is better in PHCD. He said the Iraq government subsidies HCD and this influences his choice. He is responsible for his HCB. He disclose that in Iraq GHCD, health care is free. He said he had not had a BPE in both sector, he remains neutral on whether PHCD or GHCD is/are perfect. He added that he likes doctors level of care in government while he likes managerial style in private facilities. In his opinion, Iraq GHCD can improve through better management and administration, less queuing and waiting list. He advice PHCD to provide affordable services.

China: PHCD preference was indicated by one (14.29\%) out of seven Chinese involved in this perspective survey, his reason is that it is 
employer provided though he said he can advice an acquaintance to attend any. He cannot say which of the two offers satisfactory HCD but said treatment outcome is better in PHCD because you pay more for more services. If he has all financial resources he doesn't know which to choose because he has never researched on that. Accessibility, affordability. Availability and emergency situation influences his choice of HCD. He admitted that the Chinese government subsidies HCD but he is not sure whether that influences his choice. He had had a BPE in PHCD but did not give details but said the private health facility involved claimed mistakes as been responsible. He has not accessed GHCD in china. He was silent on whether PHCD are perfect but strongly disagree that GHCD are. He liked doctors level of care in PHCD but don't know what he likes about GHCD. While he has no advice for GHCD system, he advised their private counterpart to less bureaucracy.

Australia: An Australian indicated preference for PHCD. He is one $(20 \%)$ of five Australian perspectives shared. He had accessed both health care sector in Australia and admitted that government charges are less, however he said private are better equipped, he said he can advice a friend to attend both because government subsidies cost while private is more comfortable. He said services in both sectors are the same and that if he has all financial resources he will choose PHCD because of better facilities. He also said treatment outcome are equal in both sector and that accessibility, availability and emergency situation are the factors that influences his choice of HCD. He admitted that the Australian government subsidy on health influences his choice of HCD. His parents are responsible for his HCB and he had not had any BPE in both sectors, though he disagree that both sectors are perfect. He likes both sectors for managerial style, doctors, nurses and paramedics level of care. He advice the Australian government to make HCD more accessible to those in need.

South Africa: According to a naturalized South African who have accessed both sectors, his preference is for PHCD because private is better equipped. He will advice a friend to attend PHCD because the health care is fair, better equipped and the doctors check for more times than government hospitals. He said private offers satisfactory HCD and treatment outcome is better in PHCD since facility is better and operations happens faster. He said if he has all financial resources at his disposal, he will choose private because of better care, people are more focused and hardworking and the private hospital are better equipped for any problem. He cited accessibility as the factor that influences his choice of HCD. He admitted the South African government subsidies HCD though this does not influence him. He is responsible for his HCB and had not had a BPE in PHCD.

He equally agrees that PHCD is perfect. In a sharp contrast, he said he had had a BPE in GHCD system in that he waited very long to be seen in a government hospital, in his words "people steal in government hospital". He said he likes paramedic's level of care in GHCD but likes doctors level of care in the PHCD. He advised the government to upgrade the hospitals and set aside a big budget for new equipment. He also advice PHCD to offer lower prices or financial planning to people. He generally requested for a faster response time and more time with the doctors.

\section{Preference for government health care delivery}

Analysis of this survey showed that $26.45 \%$ (32 respondents) out of the multinational respondents have preference for GHCD in their country of domicile (Figure 3).

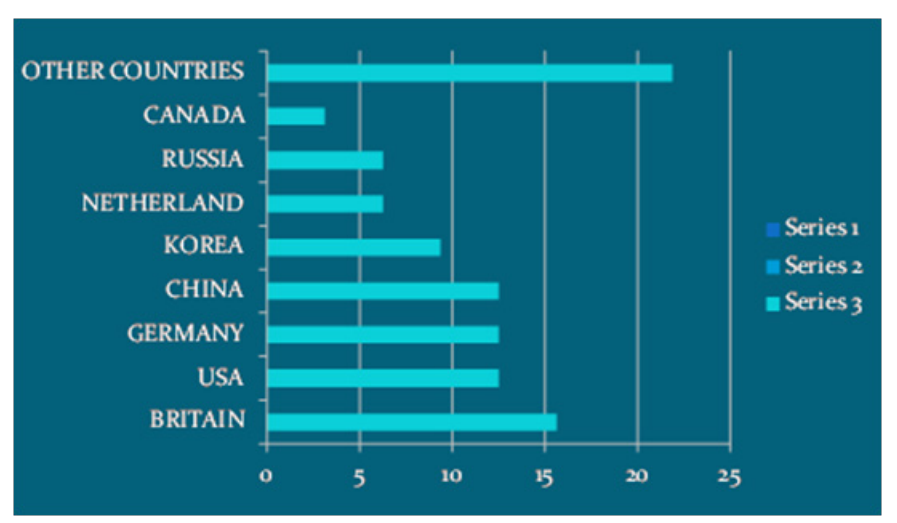

Figure 3 Percentage distribution of respondents with preference for government health care delivery.

Britain: Briton forms the largest single country group, they are $15.62 \%(5)$ respondents of those with preference for GHCD, they also formed $55.55 \%$ of Briton respondent in this study. This suggests that Briton generally accepts British GHCD. The reasons for their preference is that government charges are less, this was agreed on by all, one who have accessed both sector added that government outfit are better equipped. While $80 \%$ of them will advice an acquaintance to attend GHCD because it is cheaper and there is access to all, the remaining $20 \%$ said she will advice on any. $60 \%$ said they cannot say which of the two sector offers satisfactory $\mathrm{HCD}, 20 \%$ said government do while the remaining $20 \%$ said both sector. Concerning their choice of HCD if they have all financial resources, $60 \%$ said they don't know, of these, one said it depends on circumstances, the other said she had no experience with PHCD. The remaining 40\% said GHCD, one said because it is better and worth it if she pays the taxes.

Accessibility, availability, affordability, emergency situation and quality influence their choice of HCD. When asked on treatment outcome in both sectors, $40 \%$ said outcome are better in GHCD because of better quality, another $40 \%$ said outcome are equal because doctors have same qualification while the remaining $20 \%$ were silent. $80 \%$ said in Britain government subsidies HCD while $20 \%$ said she doesn't know . The same group of $80 \%$ said that the subsidy influences their choice of $\mathrm{HCD}$, the remaining $20 \%$ was silent. Among them, $80 \%$ said government pays for their HCB (one said National Health Service) $20 \%$ said self. Furthermore, $80 \%$ of them said they had not had BPE in GHCD. 20\% said she had that availability of doctors varies. However $40 \%$ disagree that GHCD is perfect, $20 \%$ agreed, $20 \%$ strongly disagree while the remaining $20 \%$ was silent. They have not had BPE in PHCD. $40 \%$ of them citing 1 have not access PHCD as their reason. $40 \%$ disagree that PHCD are perfect, $20 \%$ strongly disagree, $20 \%$ was neutral, the remaining $20 \%$ was silent. Their likes for GHCD include managerial style, doctors, nurses and paramedics level of care and accessibility that is free at point of delivery. All were silent on their like about PHCD some said because they have not access them before. They noted that GHCD can improve if there is shorter waiting list, more government funding and better management.

United States of America: Americans formed 12.5\%(4 respondents) in this group of respondent with preference for GHCD. They formed $10.81 \%$ of all Americans in this study implying that Americans with preference for US GHCD are in the minority. $75 \%$ of the American in this category have accessed both sectors while $25 \%$ accessed only government before. The reasons provided for the preference include 
government charges are less (an opinion shared by 50\%), government outfit are better equipped (also shared by another $50 \%$ ) though one respondent (a 17years old American) in addition said private is better equipped. Their advice for a friend on HCD differs, one said private because they are better equipped, another said government because charges are less, another said any as it is their choice, the fourth was silent. $50 \%$ said government offers satisfactory $\mathrm{HCD}, 50 \%$ admits that they cannot say.

If they have all resources financially, 50\% said they will choose government, $25 \%$ said she doesn't know which to choose while $25 \%$ (the 17 year old respondent) will choose private if she have financial resources though presently her preference is for government. The factors that influence their choices of HCD include accessibility, affordability and emergency situation.lt is worth noting that none choose availability possibly because GHCD is not widely available in the USA. $50 \%$ however stated that treatment outcome is better with government, $25 \%$ said he doesn't know because he has not used private before while $25 \%$ (the 17 year old) said treatment outcome is better with private. They all admitted that the US government subsidies HCD while 50\% said this does not influence their choice, $25 \%$ said it does while $25 \%$ (the 17 year old) said she is not sure, she said it is her employer that pays for her HCB. 50\% of these American said both self and employer pays their HCB while 50\% said employer are responsible for the payment. $75 \%$ of these respondent said they had not had BPE in GHCD while 25\% said she had but did not disclose the nature.75\% said they had not had BPE in PHCD, 25\% have not access PHCD.

When asked whether government HCD in US is perfect, $50 \%$ are neutral, 25\% disagree, 25\% strongly disagree, concerning the PHCD, $50 \%$ were neutral, $25 \%$ strongly disagree, $25 \%$ was silent. However they liked managerial style and doctors, nurses and paramedics level of care in the GHCD while in the private, they liked managerial style, doctors and nursing care. When asked how GHCD can improve, 25\% said they have no problem, another $25 \%$ said she doesn't know while $50 \%$ were silent. $75 \%$ were silent on how PHCD can improve while $25 \%$ said she doesn't know.

Germany: Germans formed $12.5 \%$ of the multinational respondents with preference for GHCD. They also formed $66.67 \%$ of all German represented in this study. This suggests that the German have a wide acceptance for GHCD. The reasons cited include government charges are less though one said in addition that private are better equipped $.50 \%$ said they will advice an acquaintance on attending GHCD because they are easier, there is good benefits with cheaper rates. $50 \%$ said they will advice on any depending on the person. $50 \%$ said HCD services are the same in both sectors, $25 \%$ said private offers satisfactory HCD while $25 \%$ said she cannot say. $50 \%$ said if they have all financial resources, they will opt for private because it is better equipped, less waiting time and better treatment, $25 \%$ said she will opt for government because it is easier, $25 \%$ said she doesn't know because she doesn't know enough about it (the sector).

Accessibility, availability, affordability and emergency situation are factors that determines their choice of HCD. $75 \%$ stated that treatment outcome is better in GHCD while $25 \%$ said outcome are equal. $50 \%$ said the government subsidies HCD while $50 \%$ don't know. $25 \%$ said the subsidy on health influences her choice of HCD, $25 \%$ said it does not, while $50 \%$ are silent. $50 \%$ self pay their $\mathrm{HCB}, 25 \%$ pays with her employer while $25 \%$ indicated her parent are responsible. $50 \%$ had had BPE in GHCD in form of very long waiting time and too long to get an appointment with a doctor. 50\% had not had a BPE in PHCD, 25\% had, she said it is too complicated to get her money back, 25\% said she had not accessed HCD. $25 \%$ agree that GHCD is perfect, $25 \%$ was neutral, $25 \%$ disagree, $25 \%$ was silent. Concerning private sector whether perfect or not, $50 \%$ are neutral, $25 \%$ agree, $25 \%$ disagree. They liked managerial style, ease, and availability as one can almost see any doctor you want to see in GHCD. In private sector, they liked doctors level of care. They advise PHCD to charge less and one said everyone should be able to get $\mathrm{HCD}$ at an affordable price.

China: Chinese formed $12.5 \%$ (4 respondents) of respondent with preference for GHCD for reasons ranging from government charges are less to government outfits are better equipped; one in addition said PHCD are better equipped. 50\% will advice on GHCD for reasons like GHCD is more varied, better equipped and charges are less, $25 \%$ will advice on both in that GHCD are good for some (in his words) normal diseases while private may be useful for some rare diseases. $25 \%$ will advice on private because PHCD gives more attention and patience although it is expensive.

All cannot say which sector gives satisfactory HCD. However $50 \%$ said private gives better treatment outcome because you can get a better service, another said because they want to remain in market private gives better practice overall. $25 \%$ said it is government, and that in China she does not really see a lot of private practice. $25 \%$ says outcome is equal in both sector. $75 \%$ said government subsidies HCD while $25 \%$ (one respondent) don't know. The influence of subsidy have different effects on them, one said it does, one said it doesn't, one is not sure, while the fourth remained silent. One self pays his HCB three pays in conjunction with employer, one cited government in addition while the other cited insurance as cosponsor of HCB. $75 \%$ had not had BPE in GHCD while one said he had in that there are too many people and services are not ideal. Of the three with no BPE in GHCD, two agree GHCD are perfect while one was neutral. The respondent with BPE in GHCD was also neutral. In the PHCD, three said they had not had a BPE, while the fourth have not accessed PHCD. 75\% agree PHCD are perfect while one was neutral. In GHCD all liked doctors level of care while in PHCD, 50\% liked doctors level of care while the remaining $50 \%$ liked nursing care. They advice government to improve the managerial level, get more doctors and nurses, less queue, one said government should call in more people to join sports, not wait for help in hospitals, and to teach more people on how to live in a healthy way. They advice PHCD to increase doctors level of care, try to provide good services with fair price while also rendering these additional services free.

Korea: Three Koreans (9.38\%) indicated preference for GHCD, they formed $27.27 \%$ of all Korean in this survey. Their unanimous reason is that charges are less, though two admitted that confidentiality is better in PHCD. All will advice a friend to attend government facilities because it is cheaper and there is confidentiality. One said government gives satisfactory $\mathrm{HCD}$, one cannot say, one was silent. These same pattern was shown by the three with respect to choice of HCD in the face of availability of all financial resources in that one will choose GHCD, one cannot say, the third was silent, the one that choose government said it is because professionalism and confidentiality is better there. Affordability is the sole factor that influences their choice of HCD. They all stated that treatment outcome is better in GHCD. Two stated that the government subsidies HCD, and both admitted the 
subsidy influences their choice. The third don't know and is not sure if it does. Their HCB is paid for by self and parent. None of them had had a BPE in GHCD and two agree GHCD is perfect while one was neutral. They had not had a BPE in PHCD either, one had not accessed PHCD. They were neutral on whether PHCD are perfect. Two liked managerial style in GHCD. They all like nursing care in PHCD and one liked managerial style in addition. They offered no advice for their health sector.

Netherland: The two Dutch in this survey preferred government sector because charges are less and are better equipped. They formed $6.25 \%$ of those with same preference. One will advice a friend to attend government stating look at cuba's situation, the other stated that he will advice on both because they are well equipped and have professional staff. One admitted that government gives satisfactory HCD while the other cannot say. They both will choose government sector if they have all financial resources, one said he never had any problem with GHCD. Accessibility, affordability, availability and emergency situation influences their choice of HCD. One said treatment outcome is equal in both and it does not really matter the other said it is better in GHCD. They both admitted that government subsidies HCD, one said this influences his choice the other is not sure if it does. They cited self, government and insurance company as being responsible for their HCB. They had both not accessed PHCD. One strongly disagree that $\mathrm{PHCD}$ is perfect the same perspective apply to GHCD the other is neutral. They had not had BPE in GHCD. They both liked doctors level of care in the GHCD, one liked paramedics level of care in PHCD while the other don't know. They advise the PHCD to reduce cost, shorten waiting list and allow doctors more time per patient. One said the improvement of the GHCD is a social case.

Russia: The two Russian in this survey both indicated preference for GHCD. They formed $6.25 \%$ of respondents with this perspective. Their reason is GHCD are better equipped though one (a 15years old Russian) added that confidentiality is better in PHCD. They both will advise an acquaintance to attend government because of lesser charges and its better. They both say government offers satisfactory HCD and one said with all financial resources available he will choose government one says he doesn't know which to choose. Accessibility and availability are factors influencing their HCD choice. They both say treatment outcome are better with government. They stated that the government subsidies HCD and that this influences their choice. One self pays his HCB while that of the $15 y$ years old is paid by the family. Both had not had a BPE in either sector and while one agrees both sectors are perfect, the $15 y$ years old remained neutral. They both liked doctors level of care in the government sector while in private one liked managerial style while the other liked doctors care. One think GHCD is the best way. They both offered no advice.

Canada: She is one of three Canadian in this survey. She formed $3.13 \%$ of respondents with preference for GHCD. She has accessed both sector before and said treatment outcome are equal and can advice an acquaintance to attend both. She also stated that services are the same in both. If she have all financial resources she will attend GHCD and accessibility is the factor that influences her choice of HCD. She disclosed that government subsidies HCD though this does not influence her. The government pays for her HCB and she has not had a BPE in both sectors. She agreed GHCD is perfect but is neutral on the PHCD. She however likes doctors level of care in both sectors.

Turkey: She is one of two Turk respondents in this study. Her preference is for GHCD because charges are less and they are better equipped. She will advise a friend to attend GHCD because it is cheaper. On the average she believed PHCD offers satisfactory HCD and if she has all resources she will choose PHCD because it is more healthy. Availability is the factor that influences her choice of HCD. She doesn't know if government subsidies health and her father is responsible for her HCB. She had not had a BPE in PHCD but disagree that they are perfect, she had had a BPE in GHCD before in that it is a crowded place. She liked doctors level of care in GHCD while in private in addition to that she likes managerial style, nurses and paramedics level of care.

France: One of three French in this survey preferred GHCD because of lesser charges and if she have all financial resources will choose same, ${ }^{7}$ she will advice a friend to attend GHCD and also believes government offers satisfactory HCD. Affordability influences her choice of HCD. According to her, government subsidies HCD and this influences her.

Serbia: The only Serbian in this survey preferred GHCD due to lesser charges, though he stated that confidentiality is better in private. He will advice a friend to attend any depending on personal experience but more so government because of low cost. He believes government offers satisfactory HCD of the two but said if he has all resources financially he will choose PHCD because of better services, though it is very costly. Affordability and emergency situation influences his choice of HCD. He said treatment outcome are equal in both sector, he said both work to help you, one might be quicker though .He doesn't know if there is subsidy on health. He equally does not know if health subsidy influences his choice. He self pays his HCB. He had not had a BPE in both sectors; he is neutral that PHCD is perfect but agree governments are. He liked doctors level of care in PHCD. He advice government on precision in delivery while private should lower cost.

Japanese: The only Japanese involved in this study prefers GHCD because of lesser charges. He will advice a friend to attend government though he cannot say which gives satisfactory HCD. If he has all financial resources, he said he will choose government because no private insurance is needed for covering charges in Japan. Availability influences his choice of HCD. He said outcome is equal in both sector. He said the government subsidies HCD and this influences his choice. He self pays his HCB. He had not had a BPE in either sector and is neutral on whether they are perfect or not. He said he cannot compare both sectors.

Taiwan: He is one of two Taiwanese involved in this study, though he had accessed both sectors, he preferred government because of lesser charges and better equipment. He will advice a friend to attend government because GHCD are quite strong though he cannot say which offers satisfactory HCD. He said if he has all financial resources, he doesn't know which to choose because it will still depend on equipment, facility and treatment, to make his choice. Accessibility and affordability are factors that influence his choice of HCD. He stated that treatment outcome is equal in both sector. He said government subsidies HCD but this does not influence him. He and his employer are responsible for his HCB and he confessed he had not accessed PHCD. He had not had a BPE in GHCD though he is neutral on whether they are perfect or not. He likes doctor's level of care in GHCD and liked managerial style and doctors and nursing care in private. He advice government to charge percentage of the income level for $\mathrm{HCD}$. 
Australia: She is one of five (20\%) Australian involved in the study. She preferred GHCD because of lesser charges. She will advise a friend to attend government though she cannot say which offers satisfactory HCD. She said if she has all financial resources she doesn't know which she will choose. Affordability influences her choice of HCD. She doesn't know if government subsidies HCD. She self pay her HCB but does not know if subsidy influences her or not. She had not access private practice before and had not had BPE in GHCD. She is neutral on whether either sector is perfect.

\section{Commonwealth of the bahamas}

She is the only Bahaman involved in this survey and her preference is for GHCD because of lesser charges. She stated that she has not accessed any of the sector before. She however said affordability is a factor that can influence her choice of HCD, she said treatment outcome is better in private. She said government subsidies health though that does not influence her. She will self pay her HCB if need arises. She however disagree that PHCD is perfect . She liked doctors level of care in GHCD.

\section{Discussion}

Health care delivery has undergone tremendous improvement from the times of Hippocrates till the present age. The national design of health care delivery in various continents and nations of the world allows for participation of both government and the private sector in health care delivery. Over the years the interaction between end users of HCD on the one hand and the providers (whether government or private) on the other hand had generated divers perspectives which had been a conscious or unconscious behaviour modifying factor in the life of the citizenry. These perspectives whether positive or negative are strong factors to consider by health care managers globally in the course of discharging their duties. While it may be practically impossible to put the perspective of over 7 billion world population down in a paper or print, it is worth it to examine what the perspective of randomly selected individuals will be like which is one of the reason why this survey was conceptualized.

There are salient points to note in this survey which include the fact that global perspective on health care delivery differs from one country to the other. Furthermore there are differences in perspective within the same country. Also individuals with the same preference for health care delivery within same country and in all countries represented in this study with multiple respondents have divergent reasons despite having same preference. The Americans (USA) that participated in this study showed their huge acceptance for private health care delivery (PHCD) in the USA. Health care delivery in the USA according to this survey is majorly private sector driven with government health care delivery (GHCD) in some situation. I am of the opinion that the perspective of the American health care researcher involved in this survey about USA HCD is worth noting since as a health care researcher she will most likely be speaking from an objective point of view. Since some of the respondents in this study are not aware if there is health subsidy in their country of domicile, it will be good if health subsidy policies of various governments worldwide is made known to the citizenry as this may be a tool to improve health care patronage especially in countries where health subsidy exist and are substantial.

Personally, 1 fell the demise of a patient due to professional negligence affects perspective, it goes a long way to bias patient and their relative's mind against health care providers whether private or government, it has the potentials of closing their mind to the other good services rendered once this occurs hence both sector should be mindful of this for the purposes of public image. It is worth noting that the submission of the French respondents on GHCD in this survey is in agreement with the World Health Organization (WHO) ranking of France as the number one HCD in the world in 2014.? The comment of the South African with preference for PHCD was rather sharp, however it should be noted that he is a naturalized citizen though whether this influenced his perspective or not could not be determined. Britons in this survey generally accepts British GHCD. The reasons for their preference is that government charges are less, this was agreed on by all, one who have accessed both sector added that government outfit are better equipped.

This suggest that the British government invest hugely in health care delivery with the hope of lesser financial returns from the citizenry since charges are less, this is a smart way of subsidizing health care as it will encourage patronage from virtually all strata of the British society. In all nation, accessibility and availability are crucial factors that need to be factored into heath care management plans early enough as urbanization programmes are embarked upon by different government of different nations as it is a prominent factor that influences the end users of HCD as seen in the various respondents perspective in this survey. Equally, the Germans involved in this survey showed huge acceptance for GHCD like the Briton because of lesser government charges. Doctors are not really indicted in almost all countries involved in this survey as the culprit for their country's health care delivery system failure or deficiency in either sector. Waiting time is a major issue that a good number of respondents are concerned with. Health care charges whether in GHCD or PHCD have a strong influence on patients preference for HCD. Government worldwide need to look into the managerial style of their HCD. The call for PHCD to reduce cost or make PHCD affordable is universal based on this survey. Lesser charges is a very common reason why people attend government sector.

Aside from the USA and Netherland, the responses/perspectives given in this survey were done outside the respondents country so 1 believe the fear of intimidation is less or absent on the part of the respondents, hence virtually all were open about their country's health care system in both sectors. However it should be noted that the perspectives shared in this survey is not that of the author but of the respondents. The fact that the study was done outside Nigeria with exclusion of Nigerians in diaspora is an additional point on credibility of this survey. It is to avoid unnecessary bias. In the second part of this article, the perspective of the subset of respondents with preference for both private and government sector will be analysed. In all, this article was written not to indict any country or government but with a perspective towards a better global health since health is wealth. The limitation of this study include the small sample size of respondents and the paucity of the number of countries involved in the study. Language barrier was another limitation as the questionnaire was printed in English, 1 remembered vividly a Spanish couple who both expressed interest in participating but could not as they only can speak and write Spanish language. In a future study more countries and respondents can be involved in the study with translation of questionnaire into other world major languages.

\section{Conclusion}

There are salient points to note in this survey which include the fact that global perspective on health care delivery differs among 
multinationals. In all countries where perspectives on health care delivery are same, there are divergent reasons for the same view. Waiting time is a major issue that a good number of respondents are concerned with. Health care charges whether in GHCD or PHCD have a strong influence on patients preference for HCD. Doctors are not really indicted in almost all countries involved in this survey as the culprit for their countries health care delivery system failure or deficiency in either sector.

\section{Acknowledgements}

I want to appreciate all the numerous multinational respondents who took time out of their schedule to fill the questionnaire without which this research work would have not been possible. I thank you all.

\section{Disclosure}

Nothing to disclose.

\section{Funding}

This project was not funded by any governmental or nongovernmental organization or body.

\section{Conflict of interest}

The author declares no conflict of interest.

\section{References}

1. World health organization. Ebola Outbreak in West Africa. Center for disease control and prevention, India: WHO; 2014.

2. World health organization. Ebola Outbreak in West Africa: Case counts. Center for disease control and prevention, USA: WHO; 2014.

3. Assessment and planning for medical evacuation by air to the EU of patients with ebola virus disease and people exposed to ebola virus. Europe; 2014.

4. Morning Break: NY Ebola Doc 'Strumming'Through Recovery. USA: Med Page Today Staff; 2014.

5. Second Dallas Nurse Positive for Ebola. USA: Med page Today; 2014.

6. Ebola Fears, Nursing Home safety. USA: Med page Today; 2014.

7. World Health Organization's Ranking of the World's Health Systems. The Patients factor.15, USA; 2014. 